\title{
Effects of Er:YAG Laser on Mineral Content of Sound Dentin in Primary Teeth
}

\author{
Cigdem Guler, ${ }^{1}$ Meral Arslan Malkoc, ${ }^{2}$ Veli Alper Gorgen, ${ }^{3}$ \\ Erhan Dilber, ${ }^{4}$ and Mehmet Bulbul ${ }^{5}$ \\ ${ }^{1}$ Department of Pediatric Dentistry, Faculty of Dentistry, Ordu University, 52100 Ordu, Turkey \\ ${ }^{2}$ Department of Prosthodontics, Faculty of Dentistry, Inonu University, 44280 Malatya, Turkey \\ ${ }^{3}$ Department of Pediatric Dentistry, Faculty of Dentistry, Inonu University, 44280 Malatya, Turkey \\ ${ }^{4}$ Department of Prosthodontics, Faculty of Dentistry, Sifa University, 35100 İzmir, Turkey \\ ${ }^{5}$ Department of Prosthodontics, Faculty of Dentistry, Eskişehir Osmangazi University, 26040 Eskişehir, Turkey
}

Correspondence should be addressed to Cigdem Guler; cigdem_zehir@yahoo.com

Received 16 June 2014; Accepted 25 July 2014; Published 14 August 2014

Academic Editor: Toni Zeinoun

Copyright (C) 2014 Cigdem Guler et al. This is an open access article distributed under the Creative Commons Attribution License, which permits unrestricted use, distribution, and reproduction in any medium, provided the original work is properly cited.

\begin{abstract}
The aim of the present study was to evaluate the mineral content of sound dentin in primary teeth prepared using an Er:YAG laser at two different power settings. Thirty-six primary second molars were used in this study. Three dentin slabs were obtained from each tooth, and the slabs were randomly divided into three groups: Group A, control; Group B, Er:YAG laser at $3.5 \mathrm{~W}, 175 \mathrm{~mJ}$, and $20 \mathrm{~Hz}$, short pulse mode; and Group C, Er:YAG laser at $4 \mathrm{~W}, 200 \mathrm{~mJ}$, and $20 \mathrm{~Hz}$, medium-short pulse mode. One dentin slab per group was used to evaluate the dentinal morphology and surface roughness values using SEM and profilometer, respectively. Mineral content in the dentin slabs were calculated by inductively coupled plasma-atomic emission spectrometry (ICP-AES). The data were analyzed by one-way analysis of variance and Tukey's HSD tests. No significant differences in $\mathrm{Ca}, \mathrm{K}, \mathrm{Mg}, \mathrm{Na}$, and $\mathrm{P}$ levels or Ca/P ratio were found among the groups $(P>0.05)$. SEM micrographs showed that surface irregularities increased with a higher power setting. The surface roughness after laser treatment in Group B and Group C was found to be similar, unlike Group A.
\end{abstract}

\section{Introduction}

Dental caries can lead to pain, infection, pulp necrosis, and tooth loss; as such, it is still considered the most prevalent oral disease during childhood and adolescence [1-3].

Cavity preparation traditionally can be performed based on mechanical and biological principles using nonrotatory and rotatory instruments. However, mechanical techniques can cause vibration, pressure, noise, and pain. Pain may be reduced by local anesthesia, but needles can also cause fear; thus, these techniques usually cause anxiety and stress in pediatric patients [4-6]. Dental pain and fear may be decreased using lasers in dentistry. It has been reported that using an erbium: yttrium aluminium garnet (Er:YAG) laser for cavity preparation produces minimal vibration and noise, minimal or no need for local analgesia, reduction of stress, and minimal removal of sound tooth structure, as well as providing a better surface for adhesive restorative materials
[6-8]. Therefore, the use of lasers in pediatric dentistry has increased recently [9-11].

Laser technology can be used in soft tissue surgery, caries prevention, caries diagnosis, cavity preparation, and endodontic treatment for children. Cavity preparation procedures have used different laser systems such as Er:YAG and erbium, chromium: yttrium scandium gallium garnet (Er,Cr:YSGG). However, changes in the dentinal morphology of primary teeth resulting from laser exposure have been reported in the literature. Zhang et al. [12] reported cracks and microfissures in the dentin surface of primary teeth prepared using a high-powered Er:YAG laser. In a different study, Zhang et al. [13] evaluated the dentinal morphology of primary teeth prepared using the Er:YAG laser with different power parameters, and they reported that there was no smear layer and the dentinal tubules were clear. In addition, they found dentin melting and cracks associated with highpowered Er:YAG lasers [13]. 
There have been recent reports in the literature regarding the mineral content of dental hard tissue prepared by different laser treatments [14-20]. In addition, Ari and Erdemir [19] reported that the adhesion of dental restorative materials to hard tissue was affected by changes in the mineral content of dentin. Therefore, change in the mineral content of dentin is important to restorative practice, bonding mechanism, and microleakage. In recent studies on the mineral contents of dental hard tissue prepared by different laser treatments, permanent teeth have been used [14-20]. Because the mineral contents of enamel and dentin in primary teeth are different from those of permanent teeth, the effect of laser on the mineral content of primary teeth may be different from that of permanent teeth as well.

There are limited studies related to mineral content of dental hard tissue in primary teeth [21-23]. In addition, there are some reports related to the concentration of trace element in primary teeth of children with healty, different conditions and/or syndromes [24-28]. However, the effect of Er:YAG laser on the mineral content of sound dentin in primary teeth has not been studied yet.

The aim of the present study was to evaluate the mineral content of sound dentin in primary teeth prepared using an Er:YAG laser at two different power settings. The null hypothesis tested was that there would be differences in the mineral content-levels of calcium $(\mathrm{Ca})$, potassium $(\mathrm{K})$, magnesium $(\mathrm{Mg})$, sodium $(\mathrm{Na})$, and phosphorus $(\mathrm{P})$ and $\mathrm{Ca} / \mathrm{P}$ ratio- of sound dentin in primary teeth prepared using an Er:YAG laser at two different power settings.

\section{Material and Methods}

2.1. Sample Preparation. All sample preparation was performed by the same operator (V.A.G.) to prevent interoperator variation. The study samples were comprised of 36 human lower primary second molars that were free of dental caries or restoration and extracted for orthodontic reasons. The study was approved by the Faculty of Medicine, Noninvasive Clinical Research Ethic Committee, Ordu University (201334). After cleaning, the teeth were mounted $1 \mathrm{~mm}$ above of cementoenamel junction, vertically in quadrangular molds with an autopolymerizing acrylic resin (Meliodent; Bayer Dental, Newbury, UK). Tooth enamel was removed with a diamond high speed cylinder bur under water cooling manually because of dentin layer being thin. The cut surface of each tooth to confirm the absence of enamel was digitally observed under light microscope, magnification X20 (Olympus SZ4045 TRPT, Osaka, Japan). Then, the occlusal thirds of the crowns were cut using a slow-speed diamond saw (Isomet; Buehler, Lake Bluff, IL) under water cooling. Three 0.6- $\mathrm{mm}$ thick, dentin slabs were obtained from each tooth for the same mineral concentrations [17] and randomly divided into three groups ( $n=36$ per group):

Group A: control group, no treatment.

Group B: dentin irradiated with an Er:YAG laser at 3.5 W, $175 \mathrm{~mJ}$, and $20 \mathrm{~Hz}$, short pulse mode.

Group C: dentin irradiated with an Er:YAG laser at $4 \mathrm{~W}, 200 \mathrm{~mJ}$, and $20 \mathrm{~Hz}$, medium-short pulse mode.
2.2. Laser Treatment. All laser applications were performed by the same operator (M.B.) to prevent interoperator variation. The laser probe was held in the same position so that it did not move across the tooth surface.

Two standard laser device modes (Fidelis Plus 3; Fotona, Ljubljana, Slovenia) were used for the laser treatment. The first, $3.5 \mathrm{~W}, 175 \mathrm{~mJ}$, and $20 \mathrm{~Hz}$, short pulse mode, was used for Group B. In this group, the laser was applied with a sapphire probe (1 mm in diameter); the contact handpiece (R14) was placed perpendicular to the surface at a distance of $1 \mathrm{~mm}$, and the entire dentin area was scanned at a speed of $1 \mathrm{~mm} / \mathrm{sec}$ with water and air cooling. For this application, the device power was set at $3.5 \mathrm{~W}$ with short pulse mode $(300 \mu \mathrm{s})$, and the repetition rate was $20 \mathrm{~Hz}$ with $175 \mathrm{~mJ}$ pulse energy.

The second, $4 \mathrm{~W}, 200 \mathrm{~mJ}$, and $20 \mathrm{~Hz}$, medium-short pulse mode, was used for Group C. In this group, the laser was applied with $4 \mathrm{~W}$ power $(200 \mathrm{~mJ}$ pulse energy with $20 \mathrm{~Hz}$ repetition rate) and with a medium-short pulse (100 $\mu \mathrm{s})$.

The average time of laser irradiation in each group was 30 seconds per specimen.

\subsection{Inductively Coupled Plasma-Atomic Emission Spectrome-} try (ICP-AES) Technique. ICP-AES experimental procedures were conducted according to Malkoc et al. [14, 15] and Secilmis et al. [16].

All dentin slabs ( $n=34$ per group) were stored at $70^{\circ} \mathrm{C}$ in cabinet desiccators (Ventisell, Italy) until they reached a constant weight. Then each specimen was weighed on an electronic balance (AX200; Shimadzu Corporation, Kyoto, Japan) and the weight was recorded [14]. Nitric acid (10 mL) and hydrochloric acid $(3 \mathrm{~mL})$ were added onto the specimens and they were digested in a microwave reaction system (Mars 5; CEM, Matthews, NC) at $180^{\circ} \mathrm{C}$ and 180 psi [16].

After calibration of the ICP-AES instrument (Vista AX, Varian, Mulgrave, Australia), $2 \mathrm{~mL}$ of solution was taken. The solutions are carried in a nebulizer with the help of a peristaltic pump. The specimen is turned into an aerosol which is carried by an argon spray. The aerosol is heated by conduction and radiation and reaches approximately $10,000^{\circ} \mathrm{C}$. Light is transferred to a detector, and every element is evaluated according to its wavelength. Five measurements were performed on each element for each solution, and the means of the measurements were calculated in milligrams per liter (parts per million) $[15,16]$. The levels of $\mathrm{Ca}, \mathrm{K}, \mathrm{Mg}$, $\mathrm{Na}$, and $\mathrm{P}$ in each specimen were determined, and the mineral contents were then calculated as percentage by weight.

2.4. Scanning Electron Microscopy (SEM) Examinations. All dentin slabs ( $n=1$ per group) were prepared for SEM (LEO EVO 40 VP; Leo Electron Microscopy Ltd., Cambridge, UK). After surface treatment, the specimens were coated (BAL-TEC SCD 050 sputter coater; BAL-TEC AG, Balzers, Liechtenstein) with gold/palladium, and micrographs were obtained.

2.5. Surface Roughness Examinations. All dentin slabs $(n=$ 1 per group) were prepared for surface roughness examinations. The mean surface roughness values ( $\mathrm{Ra}$ ) of study samples were evaluated using a profilometer (Surf Test-402 
TABLE 1: Mean percentage weights of the five elements (mean \pm standard deviation) and Ca/P ratio according to groups ( $n=34$ per group).

\begin{tabular}{lcccccc}
\hline Groups & $\mathrm{Ca}$ & $\mathrm{K}$ & $\mathrm{Mg}$ & $\mathrm{Na}$ & $\mathrm{P}$ & $\mathrm{Ca} / \mathrm{P}$ \\
\hline Group A & $21.554 \pm 1.605$ & $0.054 \pm 0.013$ & $0.587 \pm 0.165$ & $0.646 \pm 0.094$ & $9.302 \pm 0.734$ & $2.328 \pm 0.220$ \\
Group B & $22.385 \pm 1.442$ & $0.060 \pm 0.016$ & $0.647 \pm 0.092$ & $0.614 \pm 0.060$ & $9.260 \pm 0.386$ & $2.415 \pm 0.06$ \\
Group C & $23.075 \pm 1.538$ & $0.059 \pm 0.014$ & $0.621 \pm 0.118$ & $0.685 \pm 0.052$ & $9.545 \pm 0.417$ & $2.415 \pm 0.07$ \\
$P$ values & 0.103 & 0.651 & 0.579 & 0.100 & 0.450 & 0.284 \\
\hline
\end{tabular}

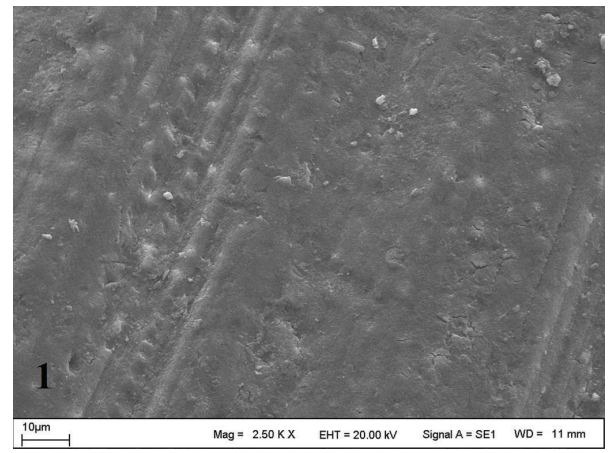

FIGURE 1: SEM micrograph of dentin surface in control group (original magnification $\times 2.50 \mathrm{k}$ ).

surface roughness tester; Mitutoyo Corp., Tokyo, Japan) in all groups. To measure the roughness value in micrometers, a diamond stylus (tip radius, $5 \mathrm{~lm}$ ) was moved across the surface under a constant load of $0.75 \mathrm{mN}$ with a speed of $0.5 \mathrm{~mm} / \mathrm{sec}$ and a range of $350 \mathrm{~lm}$. The instrument was calibrated using a standard precision reference specimen. Three traces were recorded for each specimen at three different locations in different positions (parallel, perpendicular, and oblique) giving nine tracings per sample. The average of these nine mean surface roughness measurements was used as the score for each sample. The scores were entered into a spreadsheet (Excel; Microsoft, Seattle, WA) for calculation of descriptive statistics.

2.6. Statistical Analysis. Statistical analysis of the data was performed using SPSS 16.0 for Windows (SPSS, Chicago, IL). The differences in mineral content between the groups were analyzed with one-way analysis of variance (ANOVA), and the comparison of means was performed with the Tukey HSD multiple comparisons test. Statistical differences were determined at a 95\% confidence level $(P=0.05)$.

\section{Results}

3.1. ICP-AES Evaluation. The mean percentage weights of the five elements $(\mathrm{Ca}, \mathrm{K}, \mathrm{Mg}, \mathrm{Na}$, and $\mathrm{P}$ ) in the dentin slabs are shown in Table 1. One-way ANOVA showed that there were no significant differences between $\mathrm{Ca}, \mathrm{K}, \mathrm{Mg}, \mathrm{Na}$, and $\mathrm{P}$ levels or $\mathrm{Ca} / \mathrm{P}$ ratio $(P>0.05)$ among the three groups.

3.2. SEM Evaluation. SEM views of the control (Group A) are shown in Figure 1. Er:YAG laser-treated dentin surfaces (Groups B and C) are shown in Figures 2 and 3. The surface

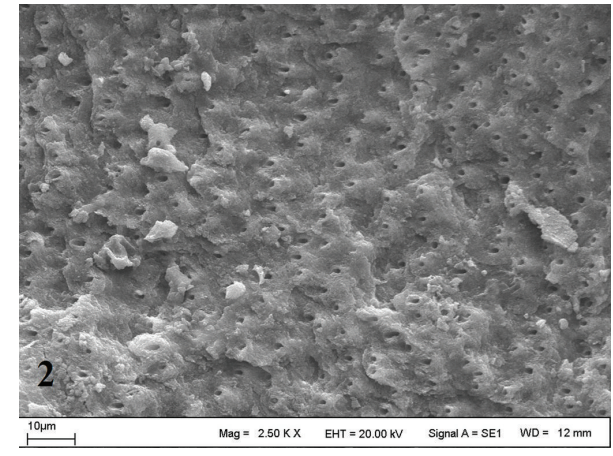

FIGURE 2: SEM micrograph of dentin surface treated with $3.5 \mathrm{~W}$ laser in Group B (original magnification $\times 2.50 \mathrm{k}$ ).

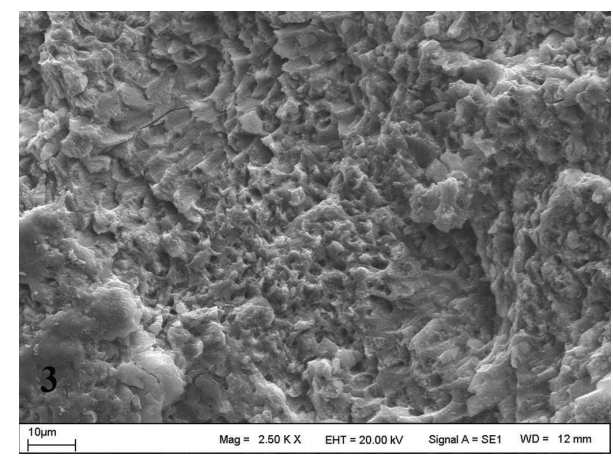

FIGURE 3: SEM micrograph of dentin surface treated with $4 \mathrm{~W}$ laser in Group C (original magnification $\times 2.50 \mathrm{k}$ ).

treated at Group C was rougher than those of Groups A and B. A rough, crystalline irradiated dentin surface could be observed in both slabs treated with the laser. This appearance was more pronounced in the Group C (Figure 3).

3.3. Surface Roughness Evaluation. The mean surface roughness values of all groups are shown in Table 2. The lower mean surface roughness value was found in Group A. The higher mean surface roughness value was found in Group C. However, similar mean surface roughness values were found in laser treatment groups (Groups B and C).

\section{Discussion}

In this study, the compositional changes $(\mathrm{Ca}, \mathrm{K}, \mathrm{Mg}, \mathrm{Na}$, and $\mathrm{P}$ ) in the sound dentin in primary teeth prepared by an Er:YAG laser at two different power settings were evaluated 
TABLE 2: Mean surface roughness values according to groups (nine tracings per sample).

\begin{tabular}{lc}
\hline Groups & $\begin{array}{c}\text { Roughness value } \\
\text { (means } \pm \text { standard deviation) }\end{array}$ \\
\hline Group A & $0.41 \pm 0.2$ \\
Group B & $1.68 \pm 0.3$ \\
Group C & $1.90 \pm 0.2$ \\
\hline
\end{tabular}

and the $\mathrm{Ca} / \mathrm{P}$ ratios of the groups were compared using ICPAES. The mean percentage weights of $\mathrm{Ca}, \mathrm{Mg}, \mathrm{Na}$, and $\mathrm{P}$ and the $\mathrm{Ca} / \mathrm{P}$ ratio of the groups were not affected by laser irradiation. Therefore, the null hypothesis was rejected.

To evaluate the mineral content of dental hard tissue, different methods can be used, such as energy dispersive spectrometer (EDS), wavelength dispersive X-ray fluorescence spectrometry (WDXRF), atomic absorption spectrophotometer (AAS), and FT-Raman spectroscopy [18, 2931]. However, the ICP-AES technique was preferred for this study due to the following advantages: (1) this technique is one the most attractive methods for the measurement of trace elements; (2) trace elements can be measured at the micrograms per liter level; and (3) multiple elements can be measured at the same time [19, 32].

Dentinal morphology is important when a tooth needs to be treated with adhesive restorative materials. The cavity preparation with the Er:YAG laser could be an alternative for fearful children in pediatric dentistry. However, use of the Er:YAG laser in both primary and permanent teeth might cause changes in dentinal morphology. Dentin consists of organic and inorganic components; the major inorganic components of dental hard tissue are $\mathrm{Ca}$ and $\mathrm{P}$ present in hydroxyapatite crystals. It has been reported that the $\mathrm{Ca} / \mathrm{P}$ ratio of dentin depends on factors such as hydroxyapatite crystal type, the availability of $\mathrm{Ca}$, the anatomic location, and the technique used $[19,33,34]$. In addition, it has been reported that altering the $\mathrm{Ca} / \mathrm{P}$ ratio of dentin can change the morphology of dentin and affect the adhesion of restorative materials to dental hard tissues $[19,35]$. According to results of this study, the $\mathrm{Ca} / \mathrm{P}$ ratios in the dentin of primary teeth were not affected by Er:YAG laser irradiation at two different power settings. However, SEM photographs indicated that the surface irregularities increased when the power setting was increased. Secilmis et al. [16] reported that surface irregularities in the dentin of permanent teeth increased when a highpowered laser was used. These results were in accordance with our findings. However, they found that $\mathrm{Ca}, \mathrm{Mg}, \mathrm{Na}$, and $\mathrm{P}$ levels and $\mathrm{Ca} / \mathrm{P}$ ratio in the dentin of permanent teeth were affected by Er,Cr:YSGG laser treatment. These results were not in accordance with our findings and might be related to the use of permanent teeth and Er,Cr:YSGG laser. Also, in the present study, surface roughness was increased after laser treatment. The higher mean surface roughness value was found in Group C: $4 \mathrm{~W}, 200 \mathrm{~mJ}$, and $20 \mathrm{~Hz}$, medium-short pulse mode. However, similar mean surface roughness values were found in laser treatment groups (Groups B and C). The increase of surface roughness value may be related to energy density of the Er:YAG laser. However, our surface roughness results should be supported by further studies using more dentin slabs.

A few studies have been conducted on the effect of Er:YAG laser on the dentinal micromorphology of primary teeth. In these laser studies, different power settings of Er:YAG laser in primary teeth were used. Kornblit et al. [36] evaluated the enamel and dentin morphology of primary teeth using an Er:YAG laser with different power parameters. They observed no carbonization or cracks, and the SEM micrographs were similar to those of permanent teeth. Flury et al. [37] compared the dentinal morphology of primary teeth using an Er:YAG laser and a diamond bur, and they reported open dentin tubules for all the laser-treated groups. These results were in accordance with our findings; we observed open dentin tubules for both laser groups when compared to the control group. However, our SEM results should be supported by further studies using more dentin slabs.

The mineral content of sound dentin in primary teeth prepared using " $3.5 \mathrm{~W}, 175 \mathrm{~mJ}$, and $20 \mathrm{~Hz}$, short pulse mode," and " $4 \mathrm{~W}, 200 \mathrm{~mJ}$, and $20 \mathrm{~Hz}$, medium-short pulse mode," of Er:YAG laser was evaluated in this study. Laser parameters used in the study were predetermined by the manufacturer's instructions. The same parameters of Er:YAG laser in primary teeth have not been studied yet. However, similar power setting of Er:YAG laser in primary teeth was used in a few studies [12, 13, 37, 38]. Zhang et al. [13] reported that laser power of less than $4 \mathrm{~W}$ at Er:YAG laser should be used for cavity preparation in primary teeth. In addition, they found that the use of the laser at $10 \mathrm{~Hz} / 200 \mathrm{~mJ}$ and $10 \mathrm{~Hz} / 300 \mathrm{~mJ}$ for cavity preparation in primary teeth is safe and effective. Monghini et al. [39] reported that Er:YAG laser irradiation of dentin in primary teeth adversely affected bond strength. In addition, they found that the increase of laser energy resulted in increasingly cratered surfaces. These results were in accordance with our findings.

Most of the studies on the effect of dental lasers on the mineral content of hard tooth tissues have been carried out on permanent teeth [14-20]. However, there are some differences between primary and permanent tooth dentin, such as thickness, number of dentin tubules, degree of mineralization, and inorganic component. The concentration of $\mathrm{Ca}$ and $\mathrm{P}$ in peritubular and intertubular dentin is lower in primary teeth than in permanent teeth. In this study, it was found that the mineral content of sound dentin in primary teeth was not affected by laser irradiation. It may be that the two laser power settings of Groups B and C did not lead to different mineral content, but they did vary in surface irregularities. The surface irregularity in Group C was higher than that in Group B. Mineral content of sound dentin in primary teeth may be change with different power settings of Er:YAG laser. Therefore, correlations among Er:YAG laser power settings, mineral content, surface irregularities, and roughness during laser preparation of dentin in primary teeth should be investigated in further studies.

From a clinical viewpoint, there are limitations concerning the correlation between in vitro and in vivo tests and also clinical usage. There are some limitations of this in vitro study. First, only two laser power settings of Er:YAG laser were used 
in this study. Mineral content of sound dentin in primary teeth may change using different power settings of Er:YAG laser. Second, only Er:YAG laser was used in this study. Mineral content of sound dentin in primary teeth may change using different laser type. Third, surface irregularities and roughness were evaluated in this study using only one dentin slab per group. The surface irregularities and roughness results may change using more dentin slabs.

\section{Conclusion}

Laser irradiation makes structural and chemical changes on the dental hard tissues. These changes alter the level of solubility and permeability of dentin. Consequently, the bond strength of adhesive systems on dentine surfaces may be affected in clinical practice. However, laser treatment did not affect the mean percentage weights of $\mathrm{Ca}, \mathrm{K}, \mathrm{Mg}, \mathrm{Na}$, and $\mathrm{P}$ or the $\mathrm{Ca} / \mathrm{P}$ ratio in any group of primary teeth in present study. Therefore, tested power settings of the Er:YAG laser is safe for cavity preparation in primary teeth.

\section{Conflict of Interests}

The authors declare that there is no conflict of interests regarding the publication of this paper.

\section{References}

[1] Y. B. O. Lima and J. A. Cury, "Seasonal variation of fluoride intake by children in a subtropical region," Caries Research, vol. 37, no. 5, pp. 335-338, 2003.

[2] P. A. Ana, L. Bachmann, and D. M. Zezell, "Lasers effects on enamel for caries prevention," Laser Physics, vol. 16, no. 5, pp. 865-875, 2006.

[3] L. K. A. Rodrigues, M. N. Santos, D. Pereira, A. V. Assaf, and V. Pardi, "Carbon dioxide laser in dental caries prevention," Journal of Dentistry, vol. 32, no. 7, pp. 531-540, 2004.

[4] C. Bader and I. Krejci, "Marginal quality in enamel and dentin after preparation and finishing with an Er:YAG laser," The American Journal of Dentistry, vol. 19, no. 6, pp. 337-342, 2006.

[5] S. Parker, "Surgical lasers and hard dental tissue," British Dental Journal, vol. 202, no. 8, pp. 445-454, 2007.

[6] U. Keller, R. Hibst, W. Geurtsen et al., "Erbium:YAG laser application in caries therapy. Evaluation of patient perception and acceptance," Journal of Dentistry, vol. 26, no. 8, pp. 649-656, 1998.

[7] K. Bitter, J. Noetzel, C. Volk, K. Neumann, and A. M. Kielbassa, "Bond strength of fiber posts after the application of erbium: yttrium-aluminum-garnet laser treatment and gaseous ozone to the root canal," Journal of Endodontics, vol. 34, no. 3, pp. 306309, 2008.

[8] G. R. Palma Dibb, S. A. Milori Corona, M. C. Borsatto, K. C. Ferreira, R. Pereira Ramos, and J. Djalma Pécora, "Assessing microleakage on class $\mathrm{V}$ composite resin restorations after Er:YAG laser preparation varying the adhesive systems," Journal of Clinical Laser Medicine and Surgery, vol. 20, no. 3, pp. 129-133, 2002.

[9] M. D. Genovese and G. Olivi, "Laser in paediatric dentistry: patient acceptance of hard and soft tissue therapy.", European Journal of Paediatric Dentistry, vol. 9, no. 1, pp. 13-17, 2008.
[10] L. C. Martens, "Laser physics and a review of laser applications in dentistry for children," European Archives of Paediatric Dentistry, vol. 12, no. 2, pp. 61-67, 2011.

[11] G. Olivi and M. D. Genovese, "Laser restorative dentistry in children and adolescents," European Archives of Paediatric Dentistry, vol. 12, no. 2, pp. 68-78, 2011.

[12] S. Zhang, T. Chen, and L. Ge, "Scanning electron microscopy was used to observe dentin morphology in primary and permanent teeth treated by erbium: yttrium-aluminum-garnet laser," Beijing Da Xue Xue Bao, vol. 43, no. 5, pp. 766-769, 2011.

[13] S. Zhang, T. Chen, and L. H. Ge, "Scanning electron microscopy study of cavity preparation in deciduous teeth using the Er:YAG laser with different powers," Lasers in Medical Science, vol. 27, no. 1, pp. 141-144, 2012.

[14] M. A. Malkoc, S. T. Taşdemir, A. N. Ozturk, B. Ozturk, and G. Berk, "Effects of laser and acid etching and air abrasion on mineral content of dentin," Lasers in Medical Science, vol. 26, no. 1, pp. 21-27, 2011.

[15] M. A. Malkoç and M. Sevimay, "Evaluation of mineral content of dentin treated with desensitizing agents and neodymium yttrium-aluminium-garnet (Nd:YAG) laser," Lasers in Medical Science, vol. 27, no. 4, pp. 743-748, 2012.

[16] A. Secilmis, S. Altintas, A. Usumez, and G. Berk, "Evaluation of mineral content of dentin prepared by erbium, chromium: yttrium scandium gallium garnet laser," Lasers in Medical Science, vol. 23, no. 4, pp. 421-425, 2008.

[17] A. Secilmis, A. Usumez, S. Usumez, and G. Berk, "Evaluation of mineral content of enamel prepared by erbium, chromium: yttrium-scandium-gallium-garnet laser," Lasers in Medical Science, vol. 25, no. 4, pp. 467-472, 2010.

[18] T. Gurbuz, Y. Ozdemir, N. Kara, C. Zehir, and M. Kurudirek, "Evaluation of root canal dentin after Nd:YAG laser irradiation and treatment with five different irrigation solutions: a preliminary study," Journal of Endodontics, vol. 34, no. 3, pp. 318-321, 2008.

[19] H. Ari and A. Erdemir, "Effects of endodontic irrigation solutions on mineral content of root canal dentin using ICPAES technique," Journal of Endodontics, vol. 31, no. 3, pp. 187189, 2005.

[20] E. Dilber, M. A. Malkoc, A. N. Ozturk, and F. Ozturk, "Effect of various laser irradiations on the mineral content of dentin," European Journal of Dentistry, vol. 7, no. 1, pp. 74-80, 2013.

[21] N. Sabel, W. Dietz, T. Lundgren et al., "Elemental composition of normal primary tooth enamel analyzed with XRMA and SIMS," Swedish Dental Journal, vol. 33, no. 2, pp. 75-83, 2009.

[22] A. Fischer, D. Wiechuła, and C. Przybyła-Misztela, "Changes of concentrations of elements in deciduous teeth with age," Biological Trace Element Research, vol. 154, no. 3, pp. 427-432, 2013.

[23] N. Youravong, R. Teanpaisan, J. G. Norén et al., "Chemical composition of enamel and dentine in primary teeth in children from Thailand exposed to lead," The Science of the Total Environment, vol. 389, no. 2-3, pp. 253-258, 2008.

[24] C. J. Brown, S. R. N. Chenery, B. Smith et al., "Environmental influences on the trace element content of teeth: implications for disease and nutritional status," Archives of Oral Biology, vol. 49, no. 9, pp. 705-717, 2004.

[25] C. de Souza-Guerra, R. C. Barroso, A. P. de Almeida et al., "Anatomical variations in primary teeth microelements with known differences in lead content by micro-Synchrotron Radiation X-Ray Fluorescence ( $\mu$-SRXRF) - a preliminary study," 
Journal of Trace Elements in Medicine and Biology, vol. 28, no. 2, pp. 186-193, 2014.

[26] D. Keinan, P. Smith, and U. Zilberman, "Microstructure and chemical composition of primary teeth in children with Down syndrome and cerebral palsy," Archives of Oral Biology, vol. 51, no. 10, pp. 836-843, 2006.

[27] G. Klingberg, C. Hagberg, J. G. NorÉn, and S. Nietzsche, "Aspects on dental hard tissues in primary teeth from patients with Ehlers-Danlos syndrome," International Journal of Paediatric Dentistry, vol. 19, no. 4, pp. 282-290, 2009.

[28] S. Rizell, H. Kjellberg, W. Dietz, J. G. Norén, and T. Lundgren, "Altered inorganic composition of dental enamel and dentin in primary teeth from girls with Turner syndrome," European Journal of Oral Sciences, vol. 118, no. 2, pp. 183-190, 2010.

[29] H. Doğan, F. Taşman, and Z. C. Çehreli, "Effect of gutta-percha solvents at different temperatures on the calcium, phosphorus and magnesium levels of human root dentin," Journal of Oral Rehabilitation, vol. 28, no. 8, pp. 792-796, 2001.

[30] N. D. Shashikiran, V. V. Subba Reddy, and M. C. Hiremath, "Estimation of trace elements in sound and carious enamel of primary and permanent teeth by atomic absorption spectrophotometry: an in vitro study," Indian Journal of Dental Research, vol. 18, no. 4, pp. 157-162, 2007.

[31] G. R. De Sant’Anna, E. A. P. Dos Santos, L. E. S. Soares et al., "Dental enamel irradiated with infrared diode laser and photoabsorbing cream: part 1-FT-raman study," Photomedicine and Laser Surgery, vol. 27, no. 3, pp. 499-507, 2009.

[32] A. Erdemir, A. U. Eldeniz, and S. Belli, "Effect of gutta-percha solvents on mineral contents of human root dentin using ICPAES technique," Journal of Endodontics, vol. 30, no. 1, pp. 54-56, 2004.

[33] M. Cohen, J. J. Garnick, R. D. Ringle, P. J. Hanes, and W. O. Thompson, "Calcium and phosphorus content of roots exposed to the oral environment.", Journal of Clinical Periodontology, vol. 19, no. 4, pp. 268-273, 1992.

[34] W. Grayson and J. R. Marsall, "Dentin: microstructure and characterization," Quintessence International, vol. 24, no. 9, pp. 606-617, 1993.

[35] I. Rotstein, E. Dankner, A. Goldman, I. Heling, A. Stabholz, and M. Zalkind, "Histochemical analysis of dental hard tissues following bleaching," Journal of Endodontics, vol. 22, no. 1, pp. 23-26, 1996.

[36] R. Kornblit, M. Bossù, D. Mari, J. P. Rocca, and A. Polimeni, "Enamel and dentine of deciduous teeth Er:YAG laser prepared. A SEM study," European Journal of Paediatric Dentistry, vol. 10, no. 2, pp. 75-82, 2009.

[37] S. Flury, T. Koch, A. Peutzfeldt, and A. Lussi, "Micromorphology and adhesive performance of Er:YAG laser-treated dentin of primary teeth," Lasers in Medical Science, vol. 27, no. 3, pp. 529-535, 2012.

[38] M. Stiesch-Scholz and M. Hannig, "In vitro study of enamel and dentin marginal integrity of composite and compomer restorations placed in primary teeth after diamond or Er: YAG laser cavity preparation," The Journal of Adhesive Dentistry, vol. 2, no. 3, pp. 213-222, 2000.

[39] E. M. Monghini, R. L. Wanderley, J. D. Pécora, R. G. Palma Dibb, S. A. M. Corona, and M. C. Borsatto, "Bond strength to dentin of primary teeth irradiated with varying Er:YAG laser energies and SEM examination of the surface morphology," Lasers in Surgery and Medicine, vol. 34, no. 3, pp. 254-259, 2004. 


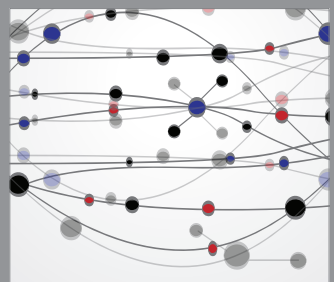

The Scientific World Journal
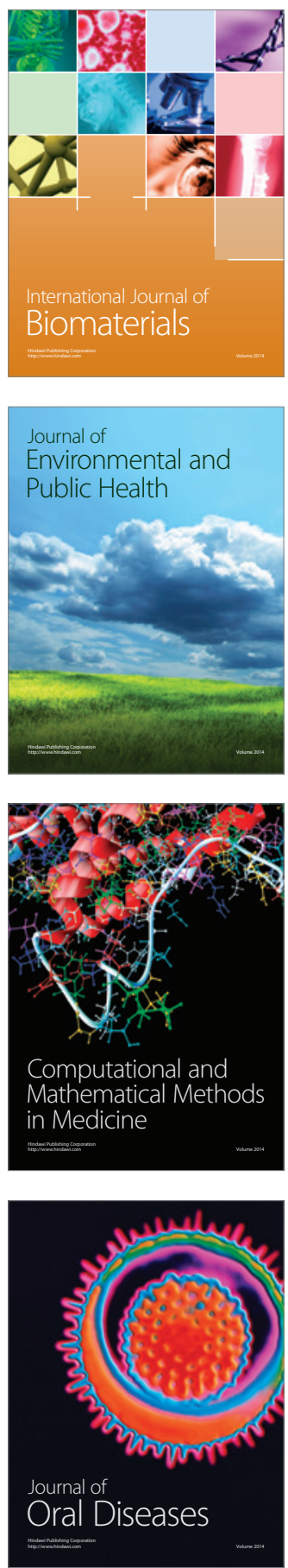
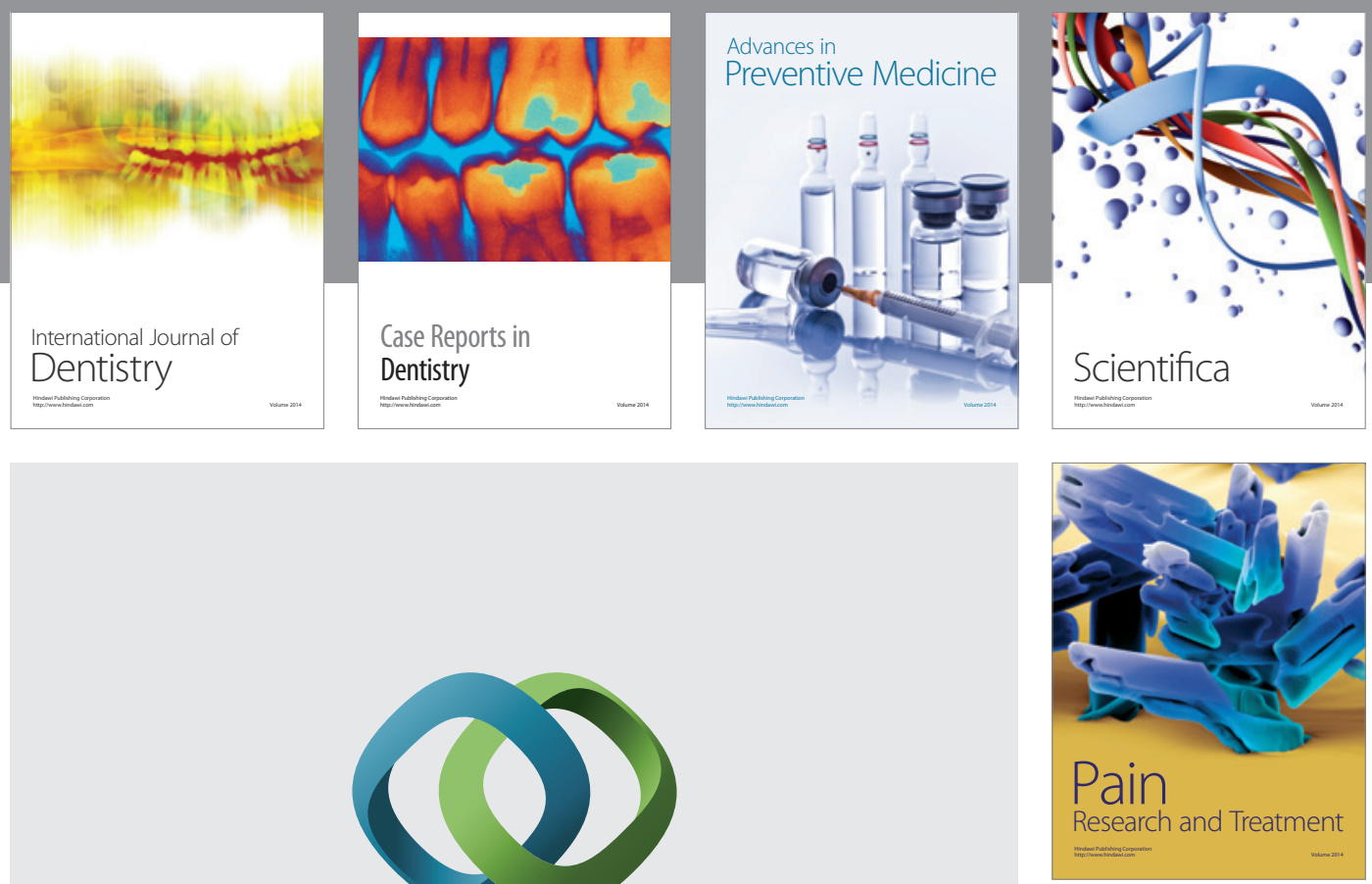

\section{Hindawi}

Submit your manuscripts at

http://www.hindawi.com
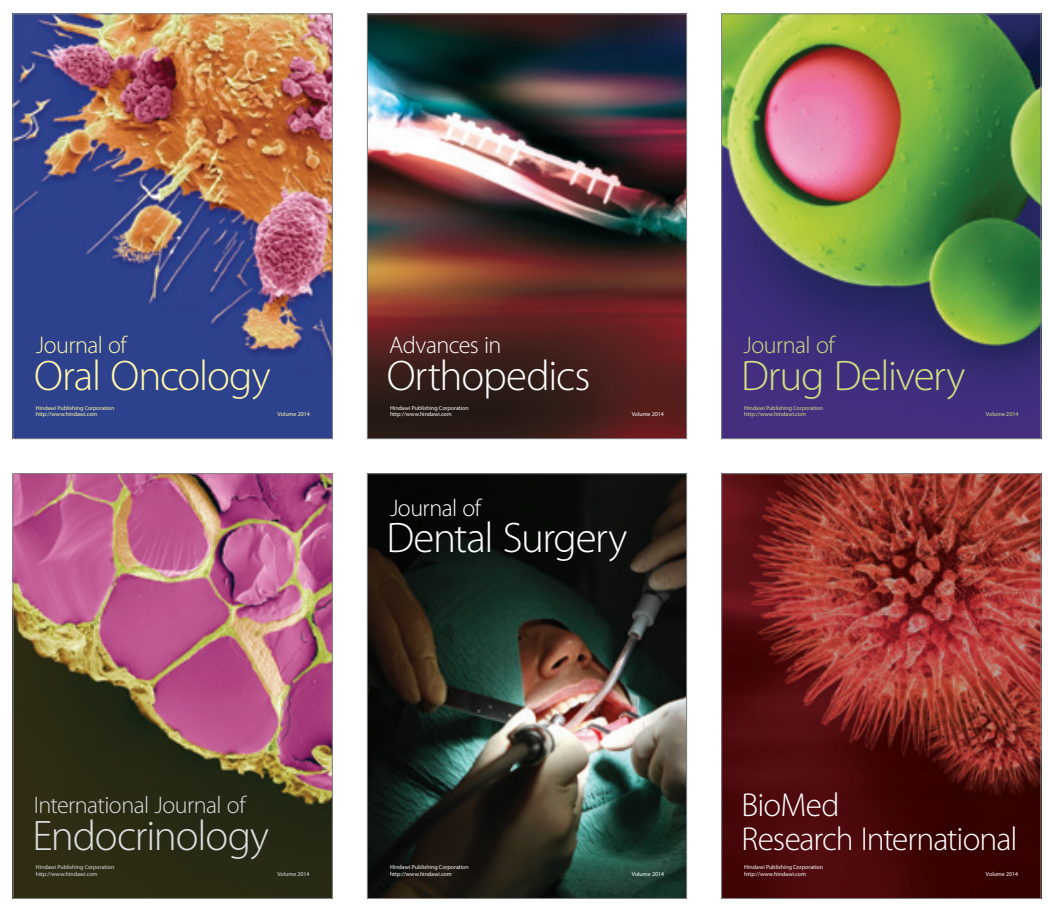

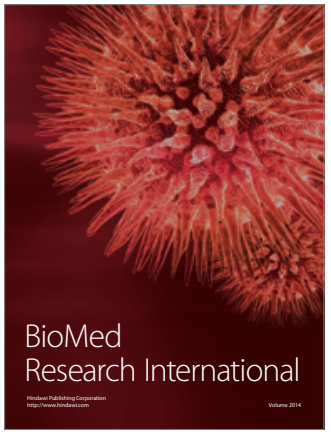

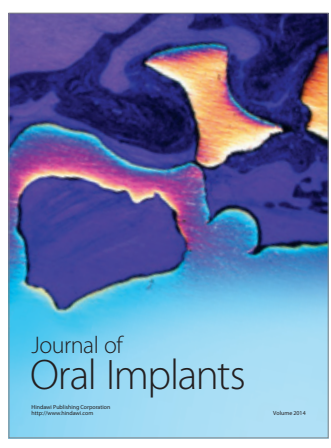
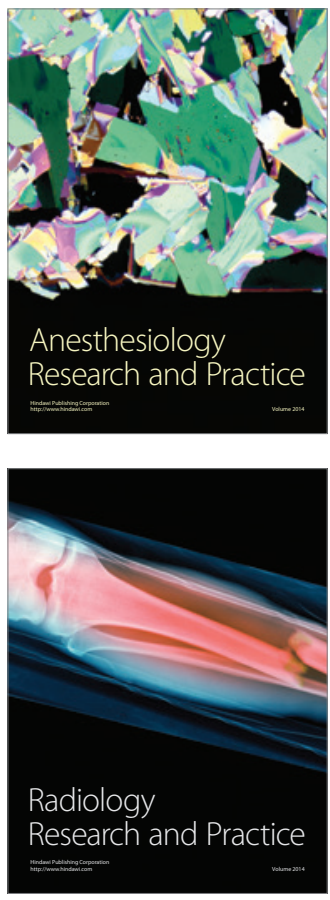